\title{
Photovoice as a Pedagogical Tool: Examining the Parallel Learning Processes of College Students and Preschool Children through Service Learning
}

\author{
Kortney Hernandez ${ }^{*}$, Ani N. Shabazian², Cathy McGrath ${ }^{2}$ \\ ${ }^{1}$ CSULA, Center for Engagement, Service, and the Public Good, 5151 State University Dr., Los Angeles, CA, USA \\ ${ }^{2}$ Loyola Marymount University, Los Angeles, CA, USA \\ Email: *kortney.hernandez139@calstatela.edu, Ani.Shabazian@Imu.edu, cmcgrath@lmu.edu
}

Received 12 September 2014; revised 8 October 2014; accepted 21 October 2014

Copyright (C) 2014 by authors and Scientific Research Publishing Inc.

This work is licensed under the Creative Commons Attribution International License (CC BY).

http://creativecommons.org/licenses/by/4.0/

c) (i) Open Access

\begin{abstract}
This study seeks to understand the effects of service learning on both young children and college students. Subsequently, quantitative and qualitative methods are employed to gain insight into how service learning coupled with a photovoice methodology can provide an empowering pedagogical practice for participants. Through the use of a Qualtrics survey and photovoice methods, this study examines the effects of service learning sampling 25 preschool age children and 39 undergraduate college students. Findings of this study provide an understanding and a platform for young children and college students to share their thoughts on service learning. Through reflection and dialogue from the participants, we begin to understand how alternative methods to education move beyond the realm of the classroom and collectively into the hands of the teacher, young children, and college students.
\end{abstract}

\section{Keywords}

Photovoice, Service Learning, Early Childhood, Volunteer Functions Inventory (VFI), Pedagogy

\section{Introduction}

The current study, using both college students and preschool children, isolates one research method/tool, photovoice methodology, and utilizes service learning as the phenomenon of study. According to Ethridge and Brans-

*Corresponding author.

How to cite this paper: Hernandez, K., Shabazian, A. N., \& McGrath, C. (2014). Photovoice as a Pedagogical Tool: Examining the Parallel Learning Processes of College Students and Preschool Children through Service Learning. Creative Education, 5, 1947-1957. http://dx.doi.org/10.4236/ce.2014.522219 
comb (2009), "few known studies have compared the active learning processes of children and adults within the same project” (p. 400). It is thought that the use of a service learning framework and photovoice methodology can provide insight into the pedagogical implications for college students and young children, which in turn may inform classroom practice. By removing educators from their traditional "expert" role and shifting the balance of expertise into the hands of college students and young children a unique opportunity develops in understanding how learning and reflection can be truly bidirectional and empowering. The authors of this article posit that through service learning and specifically the pedagogical tool of photovoice, college students and young children are able to understand, reflect on and participate in a shared learning experience. We will begin by defining the conventional use of photovoice and then delineate the adaptations that are made in the current study. Service learning will then be briefly discussed including the ways in which it was used in the current study. Further, before describing the current study, we will explain the Volunteer Functions Inventory (VFI), a measure used with the college students in our study.

\subsection{Photovoice}

Photovoice is a qualitative and participatory action research method, also referred to as photo novella, which was originally developed by Wang and Burris (1994). Photovoice, according to Wang and Burris (1994) is theoretically grounded in empowerment education, documentary photography, feminism, Freirean thought and critical consciousness. Wang and Burris (1994) first used photo novella to capture worldviews of rural Chinese women through photographs in order to inform social change. According to Strack, Lovelace, Jordan and Holmes (2010) through the use of photovoice, community members are engaged in a participatory process in which they are able to critically examine their community through photography, dialogue and action. Darbyshire, MacDougall and Schiller (2005) suggest that the use of photovoice with both adults and children allows for ideas that are different from those that typically come from interviews. Typically, this method is employed with populations that are the most marginalized or stigmatized (Wang \& Burris, 1994; Strack et al., 2010; Darbyshire et al., 2005) within society to allow for critical dialogue and action to emerge from discussions of the photographs. As it has been employed conventionally, photovoice involves placing cameras in the hands of those that have been silenced (Schell, Ferguson, Hamoline, Shea, \& Thomas-Maclean, 2009). In turn, those photographs then serve as the discussion point to critical dialogue, empowerment and action to take place. As will be discussed later, portions of the conventional photovoice method were employed with the college student participants and adapted for preschool children through the use of drawings.

\subsection{Photovoice for Young Children}

According to Piaget, activities such as drawing are key in allowing children who are in their preoperational period to represent their world; more specifically, to represent their experiences and the concepts associated with those experiences. It may be argued that the intricate fine motor abilities required to effectively use cameras for photovoice may limit young children's ability to take photographs. One of the most effective ways to encourage learning and reflection in young children may be to allow students to identify the contemporary and personal relevance of the material encountered. Moreover, the education of the whole child, which aims to integrate student's evolving selves and their culture into the education process, is now not only the mission of various K-12 schools but also many Pre-Kindergarten and early childhood education programs. This method allows children to visually represent their thoughts and their abilities while their abstract thought processes are still in their formative years. Developmentally, by the age of three, children begin drawing squiggles and simple shapes. At this stage children are capable of making six recognizable diagrams or shapes (i.e., rectangles) and seminal works such as The Psychology of Children's Art have argued that "developmentally, the diagrams indicate an increasing ability to make a controlled use of lines and to employ memory” (Kellogg, 1969: p. 45). By the time a child is four, these diagrams are coupled and put together in various combinations and the transition to pictorialism and more representational drawing begins. Research has shown, however, that children's early drawings while still primitive in form do not mirror their emotional life but rather reflect their motor limitations of the hand and arm (Fogel, 2009). Therefore, it is believed that children possess the cognitive ability to interpret their experiences and the use of the photovoice methodology can provide the platform for their voice to be heard.

From its inception, drawing has been part of early childhood education programs globally and particularly so in the U.S. This is in large part because young children seem to naturally gravitate to art areas where they are offered 
the opportunity to indulge freely into a world of self-expression. It is crucial when drawing with young children that the drawing instrument be developmentally appropriate for children in order for them to be able to use it effectively and for it to not detract from the reflection experience. Thick crayons or markers are easier for younger preschoolers to grasp because their fine motor coordination is still in its formative stages. Also unlike water colors or paint that often run, crayons and markers offer a more easily controlled process helping to facilitate young children's emerging pictorial representations. Moreover, providing the preschoolers with a blank sheet of paper to draw on does not limit or in any way inhibit their expression the way dittos or coloring books may but rather encourages them to use and, thus, help develop their very own individual voice. Furthermore, this approach is concurrent with current early childhood developmental research which affirms that asking children to "color within the lines" is not developmentally appropriate as it involves fine motor control that is well beyond most preschoolers developmental capacities (Mayesky, 2006).

Wang and Burris (1994) are credited with the origins of photovoice and they in turn, reference an original empowerment project that developed out of Peru as providing a model for their seminal photovoice study (previously termed photo novella). This original empowerment project involving illiterate/semi-literate rural women in Peru, sought to depict the living conditions of these women. Interestingly, many of the women in this project had reported never having used a pencil before or been offered the opportunity to study anything (Wang \& Burris, 1994). Booklets with simple line drawings were created that depicted the living conditions and challenges of the women. The booklets were created as coloring books and the women were given coloring pencils and crayons to complete them with (Wang \& Burris, 1994). The women discussed the colored pictures with trained community workers and had opportunities to then inform dialogue and community action. Much of the original work of Wang and Burris (1994) is credited to this original project that took place in Peru. It is reported that the women in this project also had overwhelmingly positive feedback in regards to the creative coloring activity (Wang \& Burris, 1994).

Consequently for the purposes of this study, the researchers adapted the photovoice methodology to adjust for young children's emerging fine motor abilities and as a result rather than have the young children take pictures with a camera the researchers in this study asked the children to draw pictures capturing their understanding of their service learning experiences. Drawing pictures is something much more familiar and arguably more developmentally appropriate to many preschool age children attending early childhood programs in the U.S. and children who use the same media such as markers repeatedly will over time develop the skills required to utilize them.

\subsection{Service Learning}

To achieve maximum learning potential, this study posits that teaching should provide a means to connect students' living with their learning. The pedagogical approach that allows for the effective formation of that link is the increasingly popular phenomenon of a specific model of non-traditional learning termed service learning. "Service learning is a form of experiential education in which students engage in activities that address human and community needs together with structured opportunities intentionally designed to promote student learning and development. Reflection and reciprocity are key concepts of service learning” (Jacoby, 1996, p. 5). Service learning has also been referred to as a method that progressively teaches and connects community service and academic study (Colby, Bercaw, Clark, \& Galiardi, 2009). This non-traditional method of learning places students at the forefront of an active education through experience and reflection. It is believed that in addition to the experiential learning taking place, the reflection piece is crucial in examining the effects of the service experiences on individuals.

Research on service learning as a movement suggests that it has originated rather recently and garnered acceptance and growth within the past two decades in institutions of higher education (Jacoby, 1999; Harkavy \& Hartley, 2010). Grounded in higher education, service learning has gained support within higher education in the form of federal funding (Butin, 2006), college student participation (Harkavy \& Hartley, 2010), faculty support (Butin, 2006) and organizational support (Curley \& Stanton, 2012; Campus Compact, 2013). In this study service learning is examined for its effects on college students in institutions of higher education and additionally the impact service learning has on young children. The authors of this article posit that through the pedagogical tool of photovoice coupled with service learning experiences, college students and young children are able to understand, reflect on and potentially inform and work better with their peers and within communities. As a research method, photovoice utilizes cameras in the hands of participants to gather perspectives that may not be captured through 
discussion solely or the use of surveys (Davison, Ghali, \& Hawe, 2011). Further, photovoice as a pedagogical tool allows teachers to encourage their students to meaningfully "participate and engage in understanding, caring for, and transforming the world to which they belong” (Cook \& Buck, 2010: p. 35).

Historically, institutions of higher education have had trouble providing stimulating and varying forms of service learning experiences to university students (Quezada \& Christopherson, 2005). The benefits and outcomes for college students engaging in service learning can be highlighted as a powerful experience. Therefore, it may be important to understand if service learning can provide the same experiences for young children. Consequently, this study asks: Can young children cognitively understand and articulate the experience of engaging in service? What implications does this pedagogical paradigm have for them? The rationale for using both college students and young children in the current study is to see what pedagogical outcomes emerge for both populations and, also, how can early childhood practitioners begin to construct curriculum that may utilize a pedagogical experience that differentiates from the "typical" or "traditional" college student models of service learning.

Ethridge and Branscomb (2009) utilize a service learning project in which university students use an anti-bias curriculum with young children to understand the "parallel" learning processes at work in both the children and the adults. By adapting the photovoice methodology for preschool age children and looking at how visual imagery can be employed we seek to understand the parallel learning experiences of both groups. We posit that the children and college students are apt to sharing in the pedagogical lessons uncovered through their service experiences and reflections and furthermore a communal growth and knowledge can be gained. The role of teachers can be to serve as active agents and conduits of knowledge by being the funnels through which information and opportunities are relayed to their students. As mentioned above, to optimize the service learning experience, the reflection component of learning must be critically examined and further developed.

\subsection{Volunteer Functions Inventory (VFI)}

The Volunteer Functions Inventory measures students' motivations for volunteering using six subscales and 30 items that correspond to functional motives (Clary et al., 1998). While this measure will be described in more detail below, it is important to note the effectiveness of this inventory and why it is used to measure the functional motives that undergird student motivation. Further, the six subscales from the VFI are used to compare and determine the thematic analysis of the photovoice contributions from both the college students and the preschool children participants.

\section{College Student Motivation}

According to Eppler, Ironsmith, Dingle and Errickson (2011) those that volunteer may appear to show similar reasons for volunteering but in fact may have different underlying motivations. In their study that sought to examine the effects of service learning on racist attitudes as well as the functional motives of students, it found decreased levels of racism over the semester (Eppler et al., 2011). However, Eppler and colleagues (2011) do suggest that the decrease in racism may reflect changing attitudes related to the overall general college experience. Further, Eppler and colleagues propose that volunteering motives may be more appropriate for measuring how service learning can influence students and predict whether they will continue to participate in volunteer activities. This study employed the Volunteer Functions Inventory (VFI) and found that service learning students saw their work as a way to foster personal growth and development. This was an unexpected finding by the researchers but they concluded that service learning appears to be a valuable tool in helping students define career goals, develop their identity within the larger community and adapt to social expectations (Eppler et al., 2011).

In another study that examined self-reported motivations for college students engaging in service, they found motivations such as developing skills, intrinsic, extrinsic and requirements (Chesbrough, 2011). External motivators were usually initial motivations and were found to diminish in importance by year in school and number of hours of service. Internal motivators such as humanitarian concerns were stronger motivators as year in school and number of hours increased in service. Chesbrough (2011) also found that gender played a factor with men and young students often engaging in service initially because of a requirement but once involved, they were likely to continue their involvement.

\section{The Current Study}

In the current study, service learning and photovoice methodology are coupled to compare the pedagogical effects 
of service learning on both college students and young children. This study by adapting the photovoice methodology for preschool age children looks at how visual imagery can be employed to enhance and examine learning experiences for both groups. Due to the fact that each of the researchers was connected to specific aspects of the current study, they worked to ensure that their undue influence remained as limited as possible. Two of the researchers were connected to a service learning course at each of the universities sampled and one of the researchers was connected to the university-based child care center. Therefore, the two researchers (connected to a service learning course) collected, analyzed and coded the data from the university-based child care center. In turn, the other researcher (not connected to the service learning courses) collected, analyzed and distributed the survey and aspects of the study involving the college student participants. One teacher at the university-based child care center volunteered to implement the photovoice portion of the study with each of the child participants and was trained by the researchers (not connected to the child care center) on this adapted method.

\section{Methods}

\subsection{Participants}

\subsubsection{College Student Participants}

The participants from this study reflected a convenience sample and were chosen from two universities in Southern California. The target population of undergraduate students from two Southern California universities consisted of those who were currently enrolled in a service learning course. Thirty-nine college students ranging in age from 18 - 26 years were sampled from 119 total students for participation in a Qualtrics survey. One of the universities was also, the university from which the preschool children were sampled. Of the 39 survey participants, 36\% referred to themselves as Asian, 3\% as African American, 36\% as Hispanic/Latino, 23\% as White, 3\% as Pacific Islander and $10 \%$ as other. From that, $23 \%$ were male and $77 \%$ were female. For the photovoice portion, approximately $25 \%$ of the survey participants participated. As this was an additional voluntary portion of the survey, there was no demographic information taken for the students who submitted photos.

\subsubsection{Preschool Participants}

Upon approval from the Institutional Review Board, the researchers obtained both parental consent and child assent before implementing photovoice in the classroom. Twenty-five preschool children between three-and-ahalf to five years of age were randomly selected from three different classrooms at a private non-profit universitybased childcare center. Of the 25 preschool participants, there were 12 boys and 13 girls. All photovoice sessions were audio-recorded and transcribed verbatim for analysis upon completion of the study.

\subsection{Measures}

\subsubsection{Volunteer Functions Inventory (VFI)}

An online anonymous survey was administered to 119 undergraduate students and they were given two weeks to complete it. As described earlier, the measure employed for the college student participants was the Voluntary Functions Inventory (VFI), which is often cited as the most prominent in the study of attitudes for motivation in the literature (Clary et al., 1998; Vocino \& Polonsky, 2011; Francis, 2011). The VFI protocol consists of 30 items that identify six types of functional motives: values, social, career, understanding, enhancement and protective (Vocino \& Polonsky, 2011). According to Francis (2011), over 200 journal articles cite Clary and colleagues' (1998) model for capturing the motivations of those that volunteer. While the VFI provides a solid marker for measuring the motivations of our sample of college students, the addition of photovoice was used to capture additional findings that may not be possible through survey methods. The VFI was anonymous and optional for the college student participants, however, if they decided to participate in the photovoice portion, they were informed that their responses would be used to inform practice and dialogue.

\subsubsection{Photovoice with College Students}

Photovoice as a methodology was used with both the college student participants and the young children participants to inform the impact of service learning on both populations and further determine if similar effects arose for both. The survey included a second optional portion for college students to capture their service experience through a photo and a description. This second portion of the survey prompted the college student participants to 
submit a photo and a description that depicted their service experience. Upon completion of the survey, college student participants were given the option to continue with an optional question of the survey in which they were provided with a prompt. The prompt asked simple questions based off of the SHOWeD technique and Freirean concept (Strack et al., 2010) commonly employed with photovoice methodology: 1) What do you see? 2) How does this relate to Our (Your) lives?

\subsubsection{Photovoice with Preschool Participants}

The adapted photovoice methodology used with the 25 preschool children utilized a familiar teacher at the childcare center to dialogue with the children and ask them to draw pictures reflecting on their service experiences. Initially, the teacher would initiate a discussion about what service is and if the child was familiar with it or examples of it and then both would engage in a discussion. The teacher would then provide the child with a paper and a markers or crayons to draw and reflect on the discussion they had just engaged in. The teacher followed a predetermined prompt when engaging with the child participants and used follow-up questions when needed to gain deeper insight into the thoughts of young children and how they viewed service. The children's answers were audio recorded with a tape recorder and subsequently transcribed and thematically coded.

\section{Results}

\subsection{Quantitative Findings}

Statistical analysis of the undergraduate survey collected from 39 undergraduate participants from two different universities revealed the following data. There appeared to be no statistically significant variance between income level on any of the six motivation scale variables with the exception of the scale "enhance" at the significance level of $p<0.05$. There appears to be a clear association between race (white vs. nonwhite) and all six of the motivation scales. Also interesting to note is that in terms of the order, the motivation scales of "understanding" and "values" are the most important across all groups and "career" and "enhance" fall in the middle rating while "social" and "protective" are the least important. These were the same order of themes that emerged when analyzing the qualitative data from the preschoolers. This indicates that both preschoolers and undergraduate college students may experience similar motivations when engaging in service.

\subsection{Qualitative Findings}

The college students' photo descriptions were thematically coded and five themes emerged which were then linked to the VFI functions. The children's picture transcriptions were also coded and similar themes related to the college student themes emerged. The photos and pictures were able to capture and serve as visual representations for the hypothetical constructs that emerged from the college student descriptions. These themes will be explained below and were determined by utilizing the voices of the participants. For the purposes of this section, pictures or drawings will be the term used to describe the adapted use of photovoice for children's drawings and photos/ photographs will refer to the conventional method employed with the college student participants.

The six functional motives were each linked to an emerging theme that was determined by the photovoice descriptions given by the participants. Five themes emerged: leadership, service and giving back, love and happiness, mutual/bidirectional impact and awareness of community needs. The five themes were then linked to the VFI functional motives and the following functional motives were found: understanding, enhancement and values (See Table 1).

\subsubsection{College Student Participant Themes}

Of the survey participants, approximately $25 \%$ participated in the photovoice portion. From the college student photovoice participants, $50 \%$ wrote in their description that their submission was a photo that encapsulated their entire service experience. The college student participants submitted a total of 15 photos.

Leadership. Based on the participants' descriptions, the leadership theme was defined through the use of words such as role models, social catalysts or other similarly related terms. "I think the image does a good job at depicting that we are there to lead but also that we can also have a lot of fun in the process." Leadership as a theme emerged from $50 \%$ of the participants. College student participants described their service experiences as leading others, being a leader in their service work and becoming a leader that extends beyond their service and impacts the community. 
Table 1. Linking Volunteer Functions Inventory (VFI) Motives to photovoice themes.

\begin{tabular}{cc}
\hline Photovoice Themes & VFI Functional Motives \\
\hline Leadership & Understanding \\
Service and Giving Back & Values \\
Love and Happiness & Enhancement \\
Mutual/Bidirectional Impact & Understanding \\
Awareness of Community Needs & Values \\
\hline
\end{tabular}

Service and Giving Back. This theme was visually depicted in many of the college students and children's photos and drawings. "Watching the pictured child's confidence and abilities grow, I learned how valuable service experience is to my personal emotional and spiritual growth.” Service and giving back was defined using terms such as civic engagement, service, helping, educational support, and volunteering. This theme was captured in $80 \%$ of the participants' descriptions. One college student participant description stated, "The picture encapsulates my service learning experience because it conveys multivalent aspects of civic engagement. The first instances of my service were initially predicated by the sheer happiness that came as a byproduct of my service." Another participant writes, "I selected this picture because I feel that it encapsulates my service..."

Love and Happiness. Love and happiness as a theme was coded from $50 \%$ of the participants descriptions. Words such as fun, enthusiasm, compassion, nice and excited were coded under this theme. "It is representative of many things-perseverance, inspiration, and most importantly love." Phrases such as this are illustrative of the ways in which love and happiness were captured through the use of photos and descriptions from the college students. Love and happiness were described and depicted typically as a result of the college students engaging and participating in service. One participant describes a story and an illustration of love and compassion after describing some challenges in working with a preschool child named Joe (pseudonym). "Joe presented me with this particular letter. He explains that it says, 'Dear Jessica (pseudonym), I love you. Love, Joe.' This image defines my entire experience because it shows love and compassion behind the act of serving."

Mutual/Bidirectional Impact. "I selected this image because it is a strong testament of the impact of [the program]—not just on the children we serve, but on the individuals who serve.” The mutual or bidirectional impact theme was coded for descriptions that mentioned some form of impact of their service on both parties. "... it underscores the happiness for both parties, but is also largely symbolic of the mutual impacts we have on each others lives." The mutual or bidirectional theme was found in $50 \%$ of the participants' descriptions. This theme was typically found in the college students work with young children and the idea that not only are they serving but also gaining in the process of their service. "It reminds me that we serve each other because we must. We learn from each other..."

Awareness of Community Needs. Awareness of community needs was coded from the descriptions through the use of words that described an understanding of societal needs, necessity, future impact, "not having", and the importance of education from a social justice perspective. "So many children fall behind at an early age because of their difficulty with reading. By being able to engage them at such an early age and show them that reading can be fun, we can hopefully see improvements in their early childhood literacy." Awareness of community needs was coded from $60 \%$ of the participants' responses. "... he lifted my spirits and my awareness to the needs of society. The work we do at [the program] provides the educational support needed by impoverished communities...”

\subsubsection{Preschool Participant Themes}

The researchers did not identify two of the themes explicitly in the preschool participants transcriptions or pictures as will be described below.

Leadership. Interestingly, the leadership theme was the one of two themes that was not explicitly stated or found in the young children's photovoice transcriptions.

Mutual/Bidirectional Impact. Mutual and bidirectional impact was the second theme that was not explicitly found in the children's transcriptions.

Service and Giving Back. In describing how they help their neighbor, one child participant explains, "Some- 
times I give her new dolls... Because I just think it's nice. Cause some new dolls aren't so special to me. So I give her some". In the picture drawn by the child, they drew themselves in the middle and their neighbors in a box with a room for girls and one for boys. "I made a box and I made throw them. There like this and I'll make me. And a box. And I made liked girls room now boys room. Will be a little hard to draw. There, it's all there". (See Figure 1).

Love and Happiness. Happiness could be found in the children's photovoice drawings as those that depicted pictorials of people often included smiling faces. In a conversation with one child participant, they noted that helping others when they fall down is important. "No, I say, I say this, Are you feel better? (See Figure 2) yeah and then she feel down and she feel better... Because it's nice and then if you fall, I'm gonna help you."

Awareness of Community Needs. In discussing how his mom helps other people, one child participant stated "she sends money to different countries. She donates... because they don't have clothes, or food." When asked where his mom donates food to, the child responded with "I think New York". In response to questions asked by the teacher, the child also stated that if he had the chance to help other people, he would "give them food". Furthermore, if asked if they believe every person in the world had access to food, the child responded with no and when asked why they stated, “Um, I don't know. They just don't have money”. In describing how to help those that are hungry, the child explained, "We can go to the supermarket and get them food and send it". After the discussion, the teacher offered paper and markers to the child to draw their thoughts around service, the child began to draw a purple person with long legs and when asked where they lived, the child responded "Um, in New York". In discussing the drawing with the child, they went through a list of things that the person might like to eat, "salad, chicken, broccoli, tomatoes, popcorn." Another child participant stated, "Because they don't have a home. Some other people don't have homes... Because they don't have a home and a bed... Maybe they died because homes die when they're old... you can build one." (See Figure 3).

\section{Discussion}

\subsection{Motivations behind Service}

The results of the study found that the same order of VFI motives emerged when analyzing both the quantitative and qualitative data from both groups. This indicates that both preschoolers and undergraduate college students may experience similar motivations when engaging in service. In linking the VFI functional motives and themes of the photovoice findings, understanding and values ranked as the most important values. Understanding and values were discussed as two of the highest ranking motives behind why college students engage in service. Therefore, when linking the VFI motives to the emerging themes, we see that these two values are present amongst both preschoolers and college students. Leadership and mutual or bidirectional impact could be linked to the understanding theme, which is defined as "the degree to which volunteering provides opportunities for new learning experiences and to use knowledge, skills, and abilities” (Bringle, Phillips, \& Hudson, 2004). The

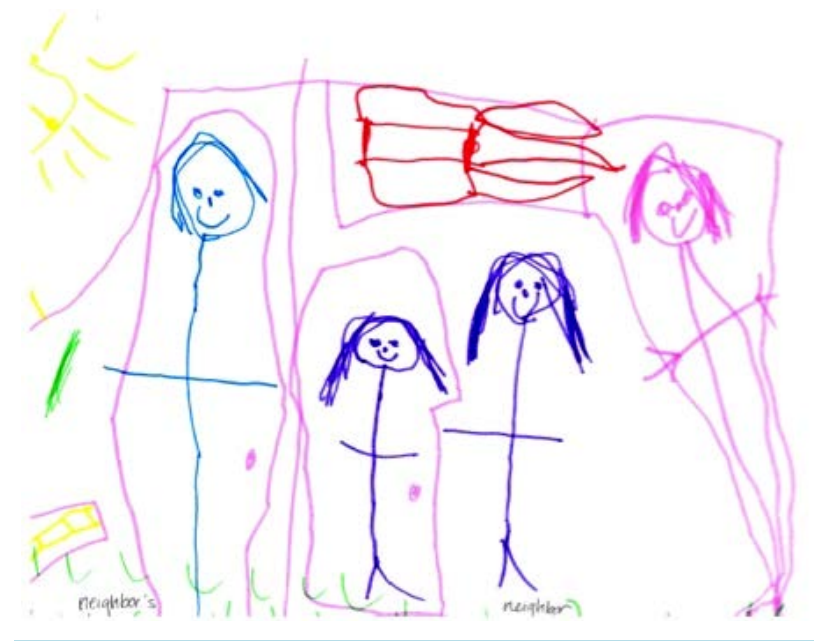

Figure 1. A child participant's drawing depicting service and giving back to her neighbor/friend. 


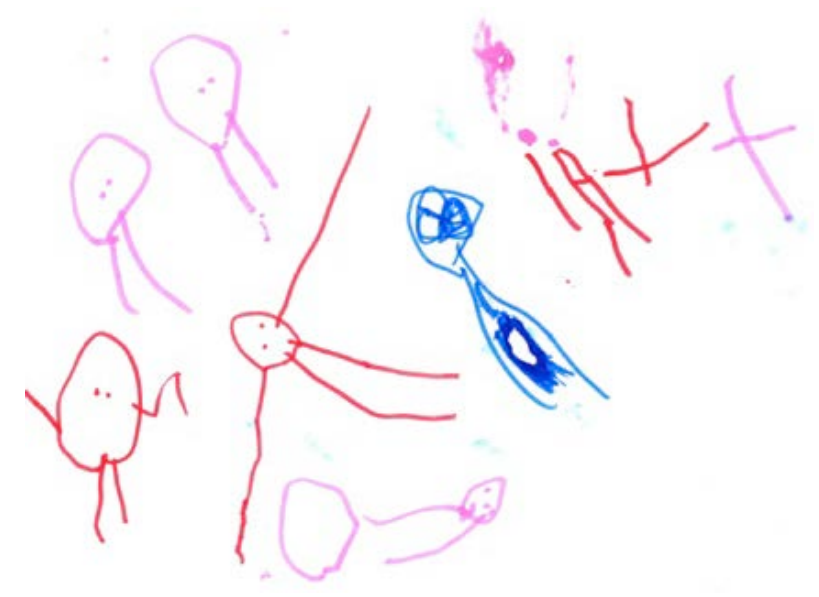

Figure 2. A child participant's drawing of helping and happiness.
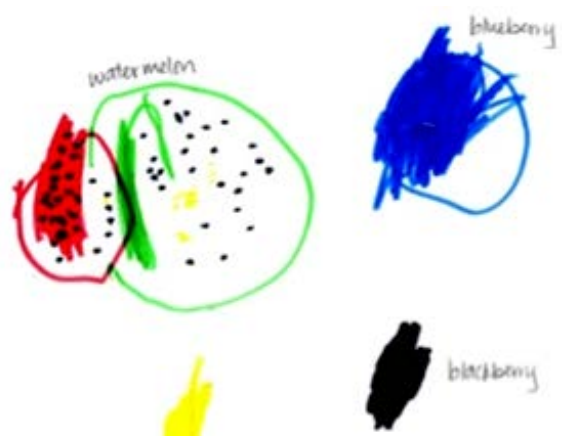

Figure 3. A child participants' drawing of food that might help those that do not have food (drawing labeled by teacher).

awareness of community needs and the service and giving back themes could both be linked to the values motive, which is defined as "the degree to which volunteering expresses altruistic and humanitarian concern for others" (Bringle, Phillips, \& Hudson, 2004). The love and happiness theme was linked to the enhancement motive which is defined as "the degree to which volunteering allows the person to avoid guilt and better cope with personal problems” (Bringle, Phillips, \& Hudson, 2004).

\subsection{Young Children}

Similarly, for the preschoolers, this study finds that the themes for the college students also applied to the children for all of the themes except two: leadership and mutual or bidirectional impact. This may highlight the need to address leadership in curriculum for young children. Explicitly explaining how young children can function as leaders in their everyday life can be an impactful and invaluable tool for teachers. It also provides young children with the language and knowledge that empowers them to share their personal stories and to serve as advocates for others. In discussing leadership, children may begin to understand and articulate their thoughts and feelings around helping others as Quezada and Christopherson (2005) state "it is well documented that community service learning has a positive effect on both the provider and recipient” (p. 14). This could potentially help children see the bidirectional impact that may exist when engaging in service. Yet, the researchers do believe that young children do exhibit leadership and understand the reciprocity and impact of their actions. This just may not have been captured fully in the current study. The photovoice portion of the study for children provides a strong case for 
the value and importance of their experiences and ability to reflect on them. It was evident in the stories of the children that they had drawn upon previous experiences to inform their current reflections on service. The ability to reflect on this further supports and provides understanding for those seeking to strengthen children's awareness of community needs, their own understanding about how they are impacted by such experiences and the impact they have on others.

Consequently, through this preschool adapted photovoice methodology, children are encouraged to express their thoughts, feelings and emotions reflecting on their service learning experience with these media. Perceived as a symbol-making activity, the children are urged to communicate their construction of concepts through their drawings. The drawings help facilitate children's understanding of their service learning experiences by offering the children developmentally appropriate tangible and concrete ideas into their less tangible abstract thoughts and feelings about service. This is in line with current instructional processes in early childhood programs where "Teachers observe children at work, listen to their responses and converse with them about their artwork to plan for their future needs and interest” (Zimmerman \& Zimmerman, 2000: p. 90). As with other forms of artwork, teachers engaging in this photovoice study are asked not to make comments or judgments about the quality of the children's art nor provide specific models or direction on how to draw specific items.

\subsection{Photovoice as a Pedagogical Tool}

To me "pedagogy" is a more complex and extensive term than "teaching," referring to the integration in practice of particular curriculum content and design, classroom strategies and techniques, a time and a space for the practice of those strategies and techniques, and evaluation purposes and methods. All of these aspects of educational practice come together in the realities of what happens in classrooms... To propose a pedagogy is to propose a political vision. (Simon, 1987: p. 371).

Using photovoice as a pedagogical tool supports the understanding that young children's development should be viewed holistically and that developmental domains must be viewed integrally and not as discrete, nonoverlapping compartments. This type of pedagogical tool also specifies that the curriculum and learning taking place in early childhood classrooms be integrated as children's development in the cognitive and social emotional domains cannot be seen as parallel and distinct but rather as truly interwoven. Moreover, many current early childhood schools of thought such as the Reggio Emilia programs believe that drawing provides a strong form of symbolic communication of children's ideas, thoughts, emotions, and perspectives. Further, service learning concepts coupled with photovoice extends children's learning outside the classroom and into the community expanding children's worlds to meaningful experiences that affect their lives and providing a safe classroom space to authentically reflect on those experiences. The primary limitation of this study is the small survey response rate from the university students, however, findings provide strong implications for the potential use of children and college students to use photovoice practices in their service and as a tool to give voice to their work. Moreover, as we immerse ourselves into the age of the digital natives, photovoice methodology promises to be a powerful tool with the millennial generation, meeting these students with the modalities that they are increasingly more comfortable with and have easier access to. Yet, beyond the use of photovoice as a powerful pedagogical tool, lies the importance of communal action and dialogue connected to reflection and reciprocity, which were all found in the current study.

\section{Conclusion}

In conclusion, service learning coupled with photovoice methods has provided a strong implication for future research to determine and understand the pedagogical impact of extending student learning beyond the realm of the classroom and into the community. The results of the current study may suggest that service learning reflection can provide an empowering pedagogical practice for those who are engaged in it and furthermore, provide the space to critically reflect on, learn from, and engage in dialogue in the classroom about experiences that take place outside the classroom—during "practice" and in students' lives.

\section{References}

Bringle, R. G., Phillips, M. A., \& Hudson, M. (2004). The Measure of Service Learning: Research Scales to Assess Student Experiences. Washington, D.C.: American Psychological Association. 
Butin, D. W. (2006). The Limits of Service Learning in Higher Education. Review of Higher Education, 29, 473-498. http://dx.doi.org/10.1353/rhe.2006.0025

Campus Compact (2013). Who We Are. http://www.compact.org/about/history-mission-vision/

Chesbrough, R. D. (2011). College Students and Service: A Mixed Methods Exploration of Motivations, Choices, and Learning Outcomes. Journal of College Student Development, 52, 687-705. http://dx.doi.org/10.1353/csd.2011.0071

Clary, E. G., Synder, M., Ridge, R. D., Copeland, J., Stukas, A. A., Haugen, J., \& Miene, P. (1998). Understanding and Assessing the Motivations of Volunteers: A Functional Approach. Journal of Personality and Social Psychology, 74, 15161530. http://dx.doi.org/10.1037/0022-3514.74.6.1516

Colby, S., Bercaw, L., Clark, A. M., \& Galiardi, S. (2009). From Community Service to Service-Learning Leadership: A Program Perspective. New Horizons in Education, 57, 20-31.

Cook, K., \& Buck, G. (2010). Photovoice: A Community-Based Socioscientific Pedagogical Tool. Science Scope, 33, 35-39.

Curley, M. F., \& Stanton, T. K. (2012). The History of TRUCEN. Journal of Higher Education Outreach and Engagement, 16, 3-9. http://www.jheoe.uga.edu

Darbyshire, P., MacDougall, C., \& Schiller, W. (2005). Multiple Methods in Qualitative Research with Children: More Insight or Just More? Qualitative Research, 5, 417-436. http://dx.doi.org/10.1177/1468794105056921

Davison, C. M., Ghali, L. M., \& Hawe, P. (2011). Insights into the School Environment That Surveys Alone Might Miss: An Exploratory Pilot Study Using Photovoice. Advances in School Mental Health Promotion, 4, 44-51. http://dx.doi.org/10.1080/1754730X.2011.9715622

Eppler, M. A., Ironsmith, M., Dingle, S. H., \& Errickson, M. A. (2011). Benefits of Service-Learning for Freshmen College Students and Elementary School Children. Journal of the Scholarship of Teaching and Learning, 11, 102-115. http://eric.ed.gov/?id=EJ956756

Ethridge, E. A., \& Branscomb, K. R. (2009). Learning through Action: Parallel Learning Processes in Children and Adults. Teaching and Teacher Education, 25, 400-408. http://dx.doi.org/10.1016/j.tate.2008.09.004

Fogel, A. (2009). Infancy, Infant, Family, and Society (5th ed.). Cornwall-on-Hudson, NY: Sloan Publishing.

Francis, J. E. (2011). The Functions and Norms that Drive University Student Volunteering. International Journal of Nonprofit and Voluntary Sector Marketing, 16, 1-12. http://dx.doi.org/10.1002/nvsm.390

Harkavy, I., \& Hartley, M. (2010). Pursuing Franklin’s Dream: Philosophical and Historical Roots of Service Learning. American Journal of Community Psychology, 46, 418-427. http://dx.doi.org/10.1007/s10464-010-9341-x

Jacoby, B. (1996). Service Learning in Higher Education: Concepts and Practices. The Jossey-Bass Higher and Adult Education Series, San Francisco: Jossey-Bass.

Jacoby, B. (1999). Partnerships for Service Learning. New Directions for Student Services, 87, 19-35. http://dx.doi.org/10.1002/ss.8702

Kellogg, R. (1969). Analyzing Children’s Art. Palo Alto, CA: Mayfield.

Mayesky, M. (2006). Creative Activities for Young Children. Belmont, CA: Wadsworth.

Quezada, R. L., \& Christopherson, R. W. (2005). Adventure-Based Service Learning: University Students’ Self-Reflection Accounts of Service with Children. Journal of Experiential Education, 28, 1-16. http://dx.doi.org/10.1177/105382590502800103

Schell, K., Ferguson, A., Hamoline, R., Shea, J., \& Thomas-Maclean, R. (2009). Photovoice as a Teaching Tool: Learning by Doing with Visual Methods. International Journal of Teaching and Learning in Higher Education, 21, 340-352. http://www.isetl.org/ijtlhe/

Simon, R. I. (1987). Empowerment as a Pedagogy of Possibility. National Council of Teachers of English, Language Arts, 64, 370-382. http://www.jstor.org/stable/41961618

Strack, R. W., Lovelace, K. A., Jordan, T. D., \& Holmes, A. P. (2010). Framing Photovoice Using a Social-Ecological Logic Model as a Guide. Health Promotion Practice, 11, 629-636. http://dx.doi.org/10.1177/1524839909355519

Vocino, A., \& Polonsky, M. J. (2011). Volunteering for Research: A Test of the Psychometric Properties of the Volunteer Functions Inventory with Online Panellists. International Journal of Public Opinion Research, 23, 508-521. http://dx.doi.org/10.1093/ijpor/edr013

Wang, C., \& Burris, M. A. (1994). Empowerment through Photo Novella: Portraits of Participation. Health Education and Behavior, 21, 171-186. http://dx.doi.org/10.1177/109019819402100204

Zimmerman, E., \& Zimmerman, L. (2000). Art Education and Early Childhood Education: The Young Child as Creator and Meaning Maker with a Community Context. Young Children, 55, 87-92. 
Scientific Research Publishing (SCIRP) is one of the largest Open Access journal publishers. It is currently publishing more than 200 open access, online, peer-reviewed journals covering a wide range of academic disciplines. SCIRP serves the worldwide academic communities and contributes to the progress and application of science with its publication.

Other selected journals from SCIRP are listed as below. Submit your manuscript to us via either submit@scirp.org or Online Submission Portal.
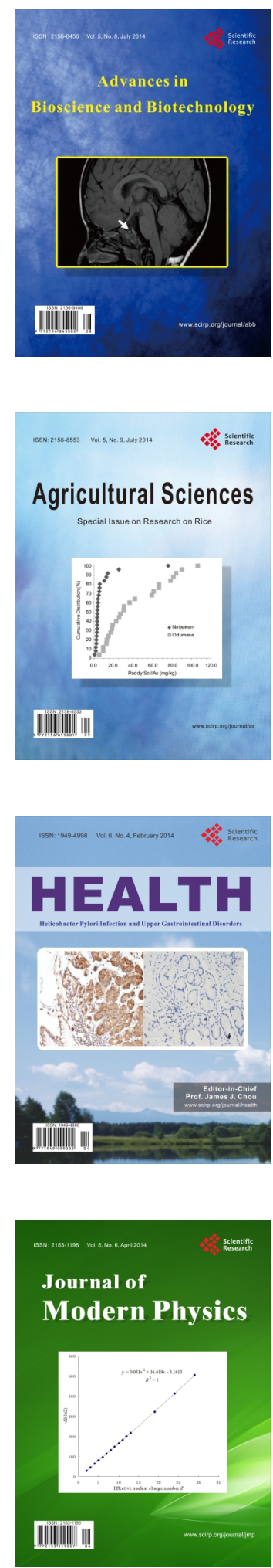
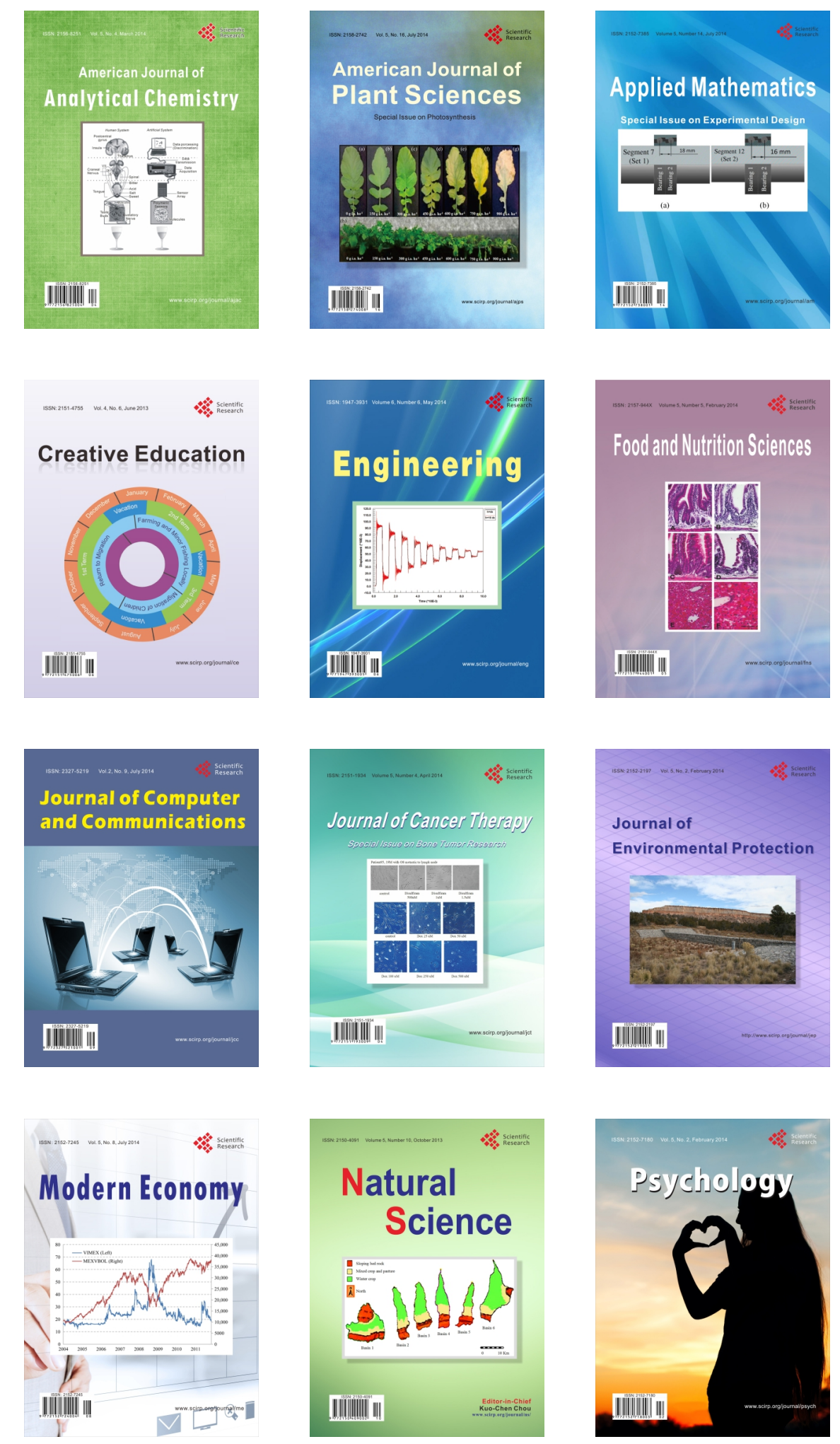